\title{
Experimental Studies upon the Reciprocal Rhythm
}

\author{
Ichiro DOHI, M.D., Yutaka DOHI, M.D., Tsutomu TADA, M.D., \\ Yahiro MITA, M.D., Ken YOSHIDA, M.D., Yasushi MATSUURA, \\ M.D., Riichi MARUYAMA, M.D., Shohji KOYAMA, M.D., \\ and Torao TAKETANI, M.D.
}

By depressing the $\mathrm{A}-\mathrm{V}$ conduction system with procain-amide, the retrograde impulse of the ventricular extrasystole was sometimes blocked or followed by a reciprocal beat. The relation between the coupling time and the kinds of extrasystoles was examined. The retrograde conduction time of the ventricular extrasystoles with reciprocal beats had negative correlation with the coupling time and the antegrade conduction time of the reciprocal beat. Similar relations were found in the experiments of the reversed reciprocal rhythm, although it was far more difficult to produce this arrhythmia under the sinus rhythm.

$\mathrm{I}^{\mathrm{N}}$ ectopic rhythms with retrograde conduction, the condition of the reciprocal rhythm rarely occurs. This arrhythmia is seen usually in nodal rhythm especially when the atrioventricular conduction system is in the depressed state by the effect of the drug or organic heart disease. The first clinical case of this arrhythmia was published by White ${ }^{1)}$ more than 40 years ago, and additional cases were reported by Decherd and Ruskin, ${ }^{2)}$ Bix, ${ }^{3)}$ Cutts, ${ }^{4)}$ Schott ${ }^{5}$ and several others. ${ }^{61-12)}$

In early days, this subject was extensively investigated experimentally upon mammalian heart by Scherf and Shookhoff, ${ }^{18)}$ although this phenomenon was first observed by Mines ${ }^{14)}$ on the ray and frog heart. Scherf and Shookhoff could produce this arrhythmia by applying successive stimuli to the ventricle under the A-V nodal rhythm or by stimulating the vagus under the same rhythm. In both instances, the V-A (ventriculo-auricular) conduction time was observed to lengthen gradually and sometimes the retrograde P-wave was followed by a reciprocal beat.

The various explanations of the underlying mechanism have been considered by several authors and they agreed with assuming longitudinal functional dissociation of A-V conduction system. When the fatigue of this tissue ensues, the impulse originating in A-V node or ventricle is transmitted in retrograde fashion to the atrium through some part of the A-V node and returns to the ventricle through the other part of the A-V node which is more depressed and in the refractory state when the retrograde conduction begins.

From the Department of Physical Therapy and Internal Medicine, Faculty of Medicine, University of Tokyo, Tokyo (Director: Prof, Yoshio OHSHIMA, M.D.). 
The existence of functional dual pathways was investigated and confirmed recently by Mendez, Gruhzit, and $\mathrm{Moe}^{15)}$ in 1956, Moe, Preston and Burlington $^{16)}$ in the same year and Rosenblueth ${ }^{17)}$ in 1958. In their experimental studies, the nature of $\mathrm{A}-\mathrm{V}$ or $\mathrm{V}-\mathrm{A}$ conduction was studied extensively and ingeniously by stimulating atria or ventricles under the various rate of atrial and ventricular rhythm with the sinus node crushed.

According to these authors, the A-V conduction fibres consist of 2 portions, one of which has shorter refractory period and permits only slower impulse transmission and the other has longer refractory period and permits faster conduction. On the basis of these facts Moe and his co-workers experimentally produced the ventricular or atrial extrasystole which returned to the respective ventricle or atrium. Thus they showed 2 forms of reciprocating impulse and established a strong evidence to the possible existence of the reversed reciprocal rhythm termed by Katz and Pick. ${ }^{18)}$ Although only a few clinical cases of the reversed reciprocal rhythm which follows the atrial ectopic impulse have been hitherto reported ${ }^{19)-23)}$ and some of them may permit other explanations, we should hereafter carefully examine the clinical records to discover these rare arrhythmias.

Dohi and co-workers have made experimental studies upon the interpolated ventricular extrasystole (I. VES.) since 1954, ${ }^{24)}$ and in 1956 they reported $^{25)}$ the relationship of experimentally produced I. VES, and the ventricular extrasystole with a reciprocal beat (R. VES.). I VES. should be recorded when the retrograde impulse of the VES. is unable to pass through the A-V conductive tissue and R. VES. should appear when the tissue only partially recovered. In correspondence with this theoretical fact, the coupling of R. VES. was longer than that of I. VES. in our experiment. It is the purpose of this paper to summarize experimental data about the I. VES. and R. VES. and refer to the analogous relationship of blocked atrial extrasystole (B. AES.) and atrial extrasystole reciprocating to the atrium (R. AES.).

\section{Methods}

Twenty dogs weighing 12 to $18 \mathrm{Kg}$. were used for the experiment. The animals were anesthetized initially with sodium thiopental $15 \sim 16 \mathrm{mg}$. $/ \mathrm{Kg}$., followed at times $5 \sim 10 \mathrm{mg} / \mathrm{Kg}$. during several hours of each experiment. Both vagi were dissected in the neck and the artificial respiration was given through a doubletube inserted in the trachea. A transverse incision was made over the fourth or fifth intercostal space and the sternum was split transversely. Non-polarizable copper-copper sulfate electrode with soft-tipped boots were put on the right atrium and the position of the atrial electrode was selected so as to describe large antegrade conducting $\mathrm{P}$-waves and to distinguish retrograde $\mathrm{P}$-waves clearly. A pair of the same kind of electrodes were used as the bipolar stimulating electrodes and were placed either on the right atrium or ventricle to elicit atrial or ventricular extrasystoles respectively. For the purpose of depressing the A-V conduction system intravenous lanatoside $\mathrm{C}$ or quinidine hydrochloride was used at the beginning of 
this study but later intravenous procain-amide was mainly used, because of its preventive effect of ventricular fibrillation following electrical stimulation applied to the ventricle.

Ciba direct writer was used to record the unipolar atrial lead.

The atrium or ventricle was stimulated with single or double electrical shock of $2 \sim 5$ milliseconds duration and the time delay of the double stimuli was varied according to circumstances, mostly between 150 and 600 milliseconds.

All experiments were performed under slow regular sinus rhythm and to minimize the influence of the change in sinus pace upon the $\mathrm{A}-\mathrm{V}$ conduction system, a continuous long record which contains many extrasystoles of various coupling was made with the fluctuation of P-P intervals mostly less than 3 per cent.

\section{RESULTS}

1. Ventricular extrasystoles:

While the sinus pace was rapid, the electrical stimulus applied to the ventricle produced only the ventricular extrasystole with a P-wave of sinus origin shortly before or after the QRS-complex (ventricular extrasystole with a compensatory pause). When the sinus pace became slower, the induced ventricular extrasystoles (VES.s) of shorter coupling time were followed by retrograde conducted $\mathrm{P}$-waves and those of longer coupling had sinus $\mathrm{P}$ waves near the QRS-complexes. Without the use of depressant drugs such as digitalis, quinidine or procain-amide, the incluced VES.s took either of these 2 forms and the interpolated ventricular extrasystole was found only exceptionally. For the I. VES. to appear, the ventricle should respond to the stimulus and the retrograde impulse should be blocked anywhere in the A-V conductive tissue.

When the depression of the A-V conduction system became severe, the retrograde conduction time became longer and sometimes the retrograde impulse of the second VES. induced in the double stimuli experiment was blocked or conducted with a remarkably long delay and again returned to the ventricle. In these states we could take a long record which contained many instances of 2 successive VES.s, the coupling time of the first being varied and the retrograde impulse of the second being blocked or producing a reciprocal beat. When the A-V conduction system became more depressed, the second stimulus produced only I. VES. and sometimes a single stimulus of various coupling time could produce I. VES. On rare occasions we could produce, in the single stimulus experiment, I. VES. or R. VES. repeatedly in a long record.

We tried to examine in these records the coupling time of both kinds of VES.s, the retrograde conduction time, and the relation between the retrograde conduction time and antegrade conduction time of the reciprocating impulse. The measured time intervals are as follows.

$\mathrm{PQ}^{\prime}$ : the time interval from the beginning of the preceding $\mathrm{P}$-wave of sinus origin to the end of $Q^{\prime}$ (ventricular extrasystole) 
$\mathrm{Q}^{\prime} \mathrm{P}_{1}$ : the time interval from the end of $\mathrm{Q}^{\prime}$ to the beginning of $\mathrm{P}_{1}(\mathrm{P}$ wave of sinus origin in the case of I. VES. or retrograde $\mathrm{P}$-wave in the case of R. VES.)

$P_{1} Q_{1}$ : the time interval from the beginning of $P_{1}$ to the beginning of $Q_{1}$ (ventricular complex directly after $\mathrm{P}_{1}$ )

$\mathrm{PP}_{1}$ : the time interval from the beginning of the preceding sinus $\mathrm{P}$-wave to the beginning of $\mathrm{P}_{1}$

Table I. Various Kinds of Measured Values in the Experiment of Interpolated Ventricular Extrasystoles and Extrasystoles with Reciprocal Beats

\begin{tabular}{|c|c|c|c|c|c|c|}
\hline & & $\mathrm{PQ}^{\prime}$ & $Q^{\prime} P_{1}$ & $P_{1} Q_{1}$ & $\mathrm{PP}_{1}$ & $\mathrm{P}_{1} \mathrm{P}$ \\
\hline 1 & $\mathrm{R}$ & 76 & 24 & 26 & 100 & 116 \\
\hline 2 & $\mathrm{R}$ & 70 & 30 & 15 & 100 & 116 \\
\hline 3 & $\mathrm{R}$ & 72 & 32 & 12 & 104 & 116 \\
\hline 4 & I & 69 & 43 & 15 & 112 & 112 \\
\hline 5 & $\mathrm{R}$ & 77 & 24 & 25 & 101 & 116 \\
\hline 6 & $\mathrm{R}$ & 75 & 26 & 20 & 101 & 108 \\
\hline 7 & $\mathrm{R}$ & 76 & 26 & 19 & 102 & 110 \\
\hline 8 & $\mathrm{R}$ & 78 & 24 & 20 & 102 & 111 \\
\hline 9 & $\mathrm{R}$ & 77 & 26 & 18 & 103 & 111 \\
\hline 10 & I & 74 & 38 & 14 & 112 & 104 \\
\hline 11 & I & 66 & 40 & 16 & 106 & 108 \\
\hline 12 & $\mathrm{R}$ & 76 & 30 & 14 & 106 & 108 \\
\hline 13 & I & 73 & 33 & 18 & 106 & 107 \\
\hline 14 & I & 69 & 38 & 16 & 107 & 108 \\
\hline 15 & I & 68 & 40 & 16 & 108 & 108 \\
\hline 16 & $\mathrm{R}$ & 82 & 24 & 24 & 106 & 108 \\
\hline 17 & I & 71 & 37 & 17 & 108 & 107 \\
\hline 18 & I & 72 & 34 & 16 & 106 & 107 \\
\hline 19 & I & 71 & 37 & 16 & 108 & 109 \\
\hline 20 & $\mathrm{R}$ & 84 & 24 & 22 & 108 & 108 \\
\hline 21 & I & 70 & 38 & 16 & 108 & 108 \\
\hline 22 & I & 73 & 34 & 16 & 107 & 108 \\
\hline 23 & I & 78 & 30 & 19 & 108 & 110 \\
\hline 24 & I & 77 & 31 & 17 & 108 & 109 \\
\hline 25 & $\mathrm{R}$ & 83 & 27 & 19 & 110 & 108 \\
\hline 26 & I & 73 & 36 & 17 & 109 & 108 \\
\hline 27 & I & 74 & 35 & 17 & 109 & 109 \\
\hline 28 & I & 71 & 38 & 17 & 109 & 109 \\
\hline 29 & I & 69 & 40 & 16 & 109 & 108 \\
\hline 30 & I & 70 & 40 & 15 & 110 & 108 \\
\hline 31 & I & 76 & 32 & 18 & 108 & 108 \\
\hline 32 & $\mathrm{R}$ & 79 & 24 & 22 & 103 & 108 \\
\hline
\end{tabular}


In the record of double stimuli experiment two VES.s are expressed as $Q^{\prime}$ and $Q^{\prime \prime}$.

$Q^{\prime} Q^{\prime \prime}$ : the time interval from the end of $Q^{\prime}$ to the end of $Q^{\prime \prime}$

$\mathrm{P}_{1} \mathrm{Q}^{\prime \prime}$ : the time interval from the beginning of $\mathrm{P}_{1}$ to the end of $\mathrm{Q}^{\prime \prime}$

$\mathrm{Q}^{\prime \prime} \mathrm{P}_{2}$ : the time interval from the end of $\mathrm{Q}^{\prime \prime}$ to the beginning of $\mathrm{P}_{2}$ ( $\mathrm{P}$-wave of sinus origin when the retrograde impulse of $\mathrm{Q}^{\prime \prime}$ is blocked or retrograde $\mathrm{P}$-wave when $\mathrm{Q}^{\prime \prime}$ produces a reciprocal beat)

$\mathrm{P}_{2} \mathrm{Q}_{2}$ : the time interval from the beginning of $\mathrm{P}_{2}$ (retrograde $\mathrm{P}$-wave of $\left.\mathrm{Q}^{\prime \prime}\right)$ to the beginning of the ventricular complex of the reciprocal beat

A) The coupling time of VES. and its retrograde conduction

Fig. 1. A. illustrates a continuous record of 4 VES.s. The first is the I. VES. and the fourth is the R. VES. The measured time intervals are shown in Table I. Fig. 1. B. shows the varying lengthening of the conduction time $\left(\mathrm{P}_{1} \mathrm{Q}_{1}\right)$ of the first sinus impulse after the I. VES. Fig. 2 is the illustration of the double stimuli experiment, the interval of 2 successive stimuli being kept fairly constant and the first stimulus being applied in the various phase of diastole.

The distribution of $\mathrm{PQ}^{\prime}$ measured in the single stimulus experiment is illustrated in Fig. 3. Here we see the tendency that early VES.s take the form of I. VES. and late VES.s the form of R. VES. A similar relationship exists in the case of double stimuli experiment. In this case the conductivity of the A-V conduction system varies according to the coupling of each stimulus. The influence of the first stimulus is examined with the fairly constant time delay of the second stimulus. Fig. 4 illustrates the distribution of $\mathrm{PQ}^{\prime}$. The retrograde conduction is completely blocked, partially conducted with a reciprocal beat, or conducted through the whole pathway according to the coupling of the first stimulus. Similar relation is found in Fig. 4. B., which illustrates the distribution of the coupling of the second stimuli measured as $\mathrm{P}_{1} \mathrm{Q}^{\prime \prime}$ for the purpose of convenience. In 14 out of 16 cases, in which 2 or 3 kinds of VES.s were recorded, the above mentioned relationship was observed although narrow range of overlapping existed near the boundary.

B) Retrograde conduction time of the VES.

In each experiment in which R. VES.s and VES.s with retrograde Pwaves not returning to the ventricles were recorded, the distribution of $Q^{\prime} P_{1}$ or $Q^{\prime \prime} P_{2}$ was examined. As illustrated in Fig. 5, the retrograde conducted impulse returns to the ventricle when the conduction rate is slower.

In most cases there are negative correlation between retrograde conduction time of R. VES. and its couplig time.

C) Antegrade conduction time of the reciprocal beat

The point where the retrograde impulse engages another antegrade pathway is not known in this experiment. We regarded the beginning of $\mathrm{P}_{1}$ as the time when the retrograde impulse reached the upper end of the $\mathrm{a}-\mathrm{v}$ conduction system. On the assumption that the returning impulse engages the antegrade pathway near the upper end of the conduction system, 


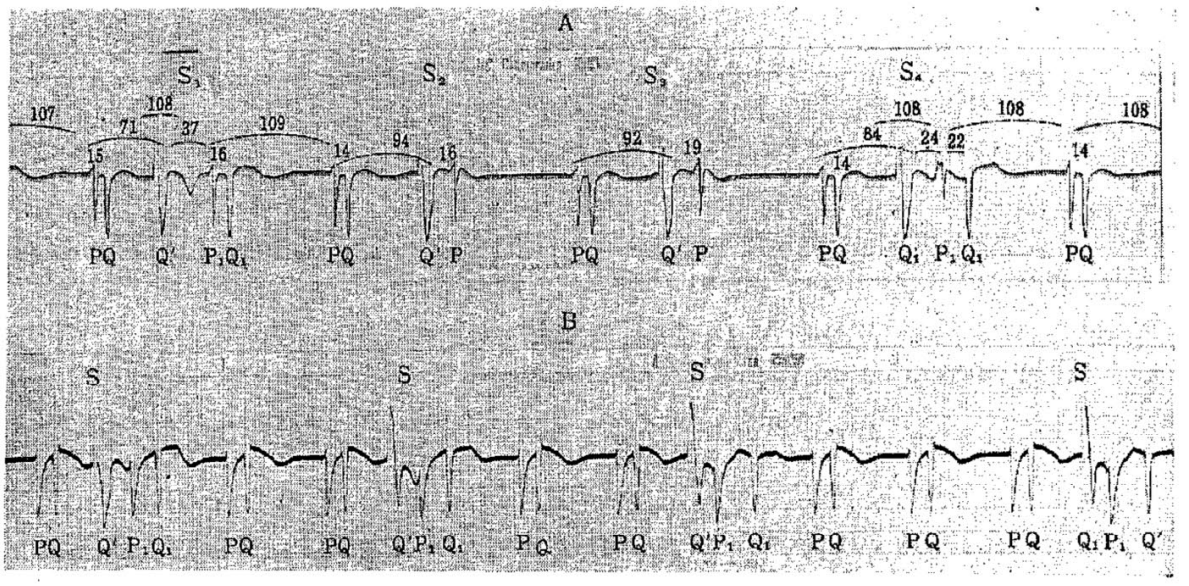

Fig. 1. A: The continuous record of the single stimulus experiment. $S_{1}$ produces an interpolated ventricular extrasystole. $S_{2}$ and $S_{3}$ produce VES.s with compensatory pauses. $\mathrm{S}_{4}$ produces VES. with a reciprocal beat.

B: The four stimuli $\left(\mathrm{S}_{1} \sim \mathrm{S}_{4}\right)$ produce I. VES.s. As the coupling time of VES. lengthens, the PQ interval which follows the VES. becomes longer.

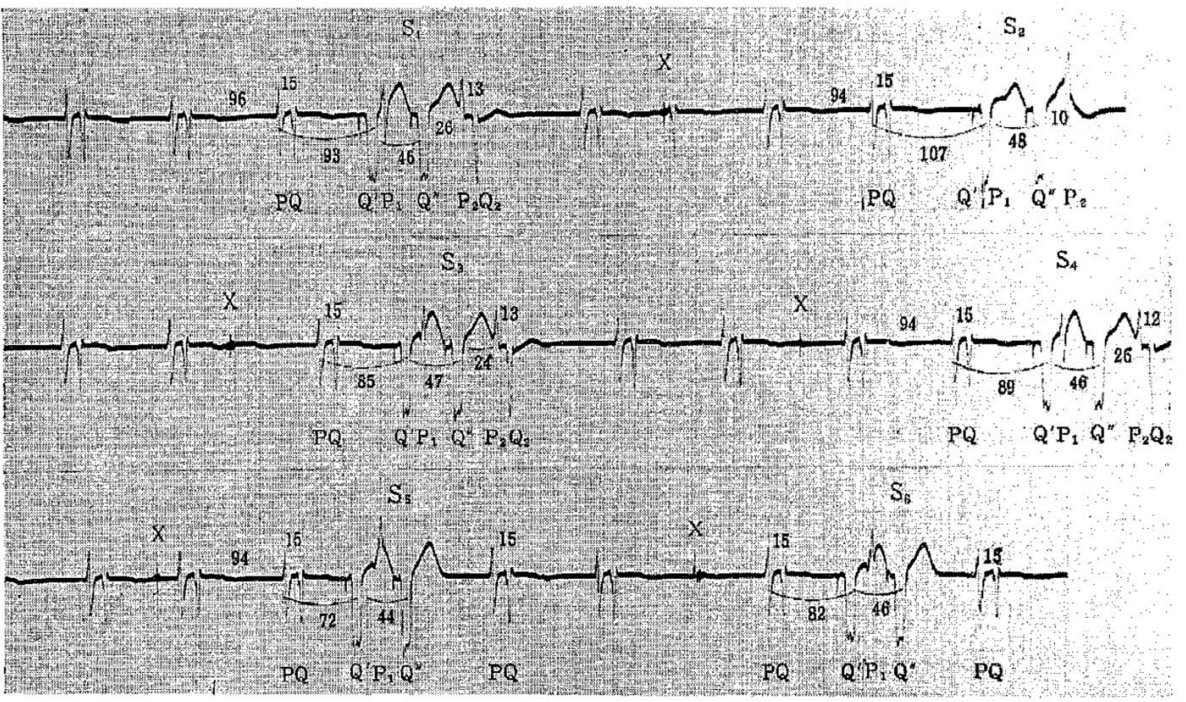

Fig. 2. The double stimuli experiment. Each of six stimuli produces two successive VES.s ( $Q^{\prime}$ and $Q^{\prime \prime}$ ). The interval between $Q^{\prime}$ and $Q^{\prime \prime}$ is fairly constant. According to the coupling time of $Q^{\prime}$, the retrograde impulse of the second VES. produces a reciprocal beat $\left(\mathrm{S}_{1}, \mathrm{~S}_{8}, \mathrm{~S}_{4}\right)$ or only the retrograde $\mathrm{P}$-wave $\left(\mathrm{S}_{2}\right)$ or cannot reach the atrium $\left(S_{5}, S_{6}\right)$. The recording is interrupted for several seconds at the mark $\mathrm{X}$, to make least the influence of each stimulation upon the next one.

the $P_{1} Q_{1}$ was selected as the antegrade conduction time of the reciprocal beat.

As illustrated in Fig. 6. A., negative correlation was found between 


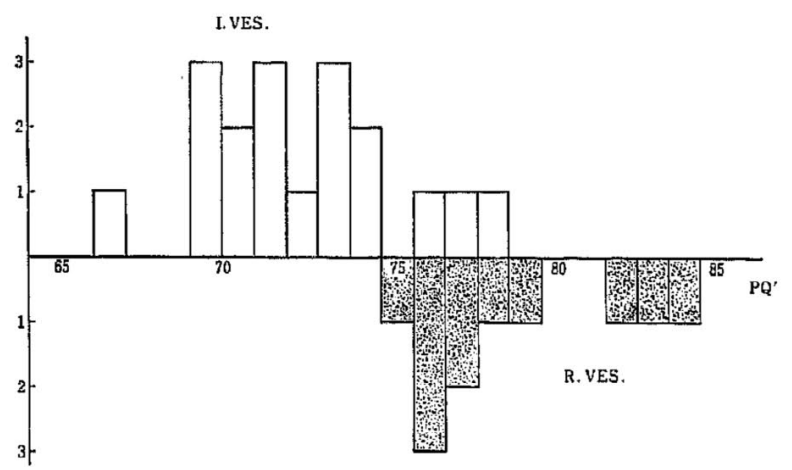

Fig. 3. Distribution of $\mathrm{PQ}^{\prime}$ in the single stimulus experiment. The abscissa is the time interval $\mathrm{PQ}^{\prime}$ measured in 1/100 second, and the ordinate is the number of VES. The distribution of both kind of VES.s shows narrow range of overlapping between 75 and 78 .
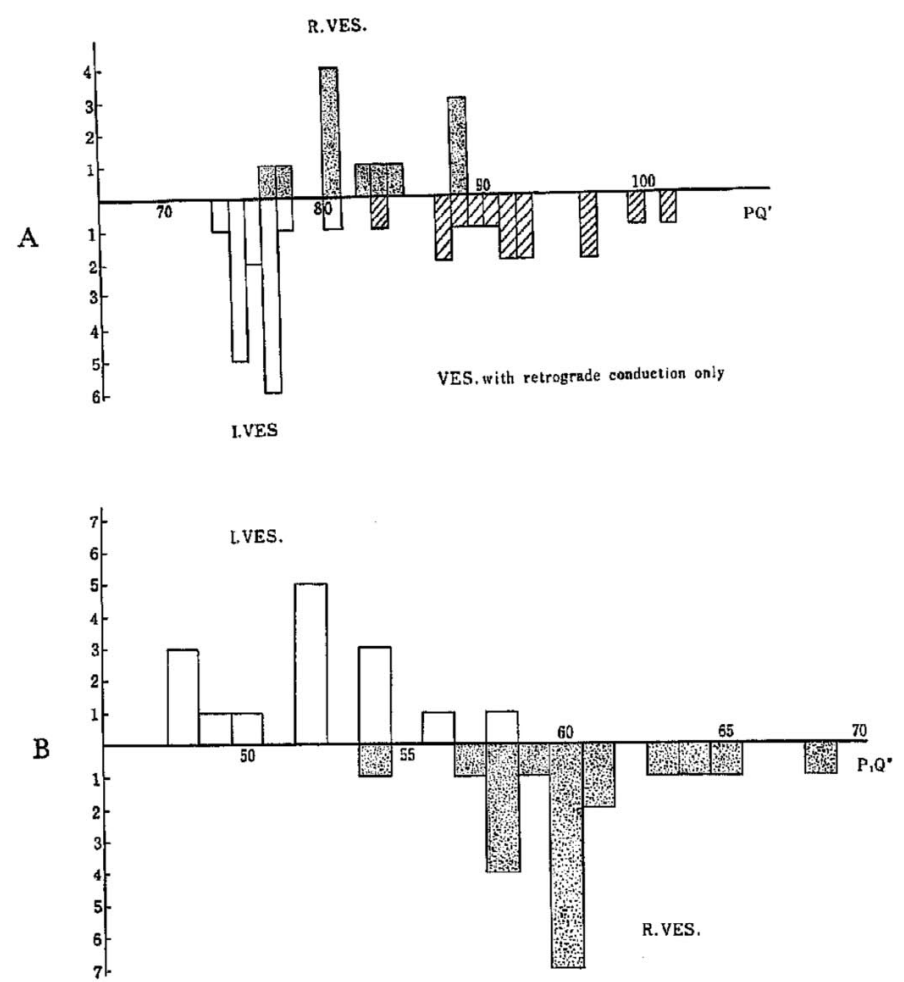

Fig. 4. A: Distribution of $\mathrm{PQ}^{\prime}$ in the double stimuli experiment. The scale of co-ordinate is as in Fig. 3. In this case $Q^{\prime} Q^{\prime \prime}$ fluctuates between 63 and 66 . According to the varying coupling of $Q^{\prime}$, the second stimulus produces I. VES., $R$. VES., or VES. with a retrograde P-wave only.

B: Similar relation as Fig. 4. A. In this experiment $Q^{\prime} Q^{\prime \prime}$ varies in a wide range and the fluctuation of the coupling of $Q^{\prime}$ is small. 


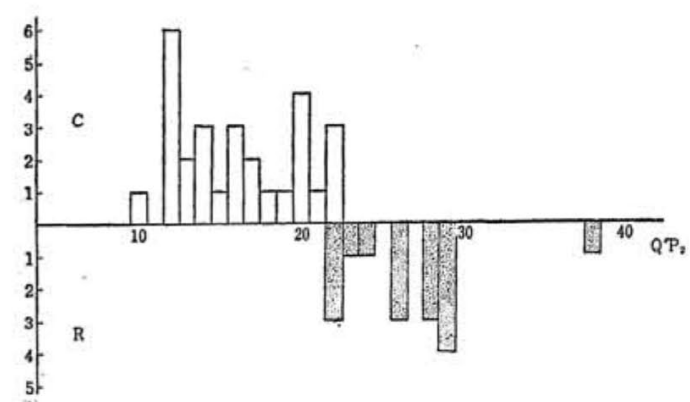

Fig. 5. Retrograde conduction time $\left(Q^{\prime \prime} \mathrm{P}_{2}\right)$ of R. VES. and VES. with retrograde P-wave not returning to the ventricle. Those VES.s with longer $Q^{\prime \prime} \mathrm{P}_{2}$ produce reciprocal beats.

$\mathrm{R}$ : VES. with a reciprocal beat

C: VES, with a retrograde P-wave only

A

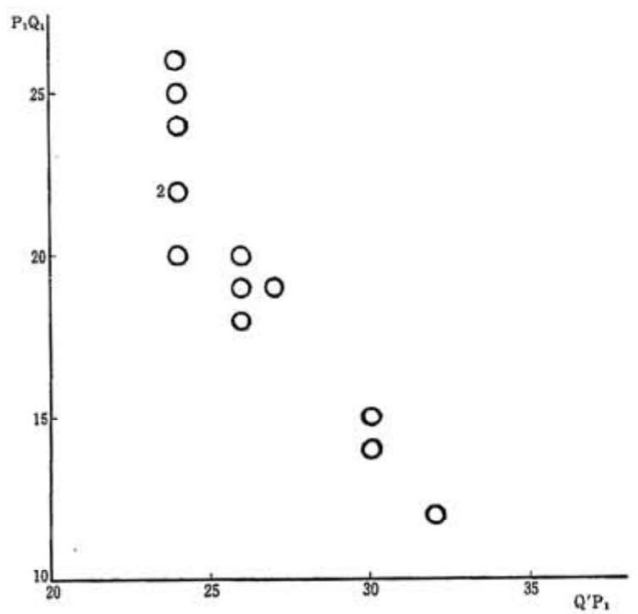

B

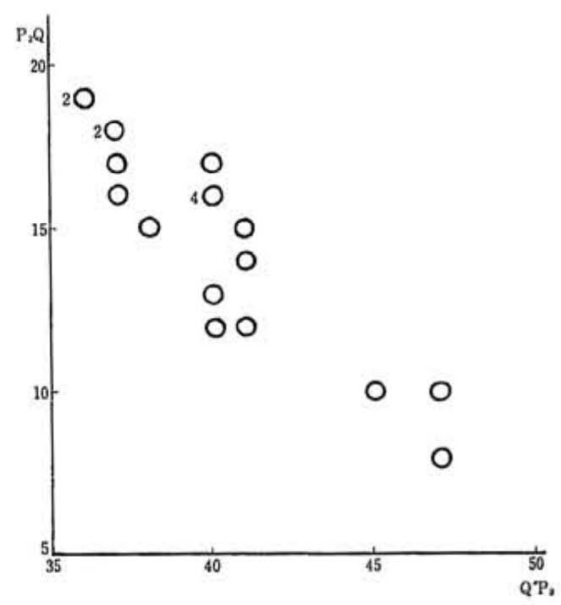

Fig. 6. A: Correlation of retrograde conduction time $\left(Q^{\prime} P_{1}\right)$ and the antegrade conduction time of the reciprocal beat measured as $P_{1} Q_{1}$ for convenience' sake.

B: Similar relation in the case of double stimuli experiment. Time scale in 1/100 second. The figure near the circle indicates the number of points having the same co-ordinates.

$\mathrm{Q}^{\prime} \mathrm{P}_{1}$ and $\mathrm{P}_{1} \mathrm{Q}_{1}$ in the single stimulus experiment, and similar relation was found in the double stimuli experiment as shown in Fig. 6. B. Such relationship existed in 12 of 16 cases.

D) The relation of the coupling time of I. VES. and the conduction time of the next sinus impulse

Fig. 7 illustrates that there is negative correlation between $Q^{\prime} \mathrm{P}_{1}$ and $P_{1} Q_{1}$. Since the sinus pace is kept constant, the I. VES. with longer coupling time has shorter $\mathrm{Q}^{\prime} \mathrm{P}_{1}$ interval, and we know from Fig. 7 that the later 


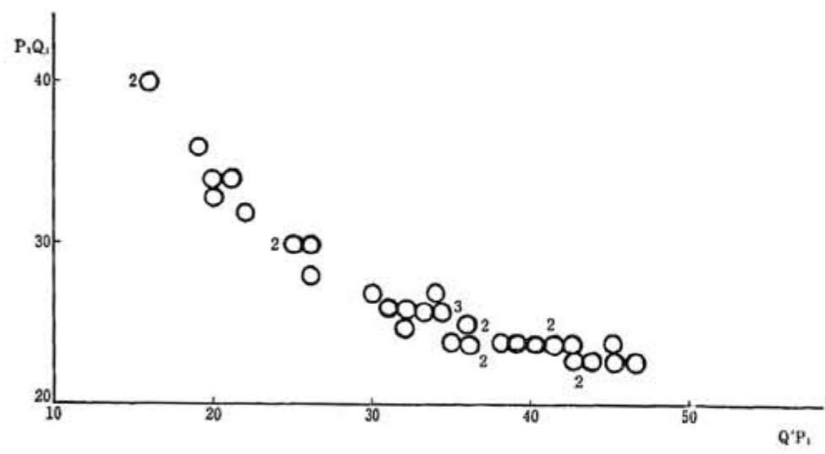

Fig. 7. The relation of the coupling of the I. VES, and the antegrade conduction time of the next sinus impulse. Instead of the coupling time, $Q^{\prime} P_{1}$ is plotted as the abscissas.

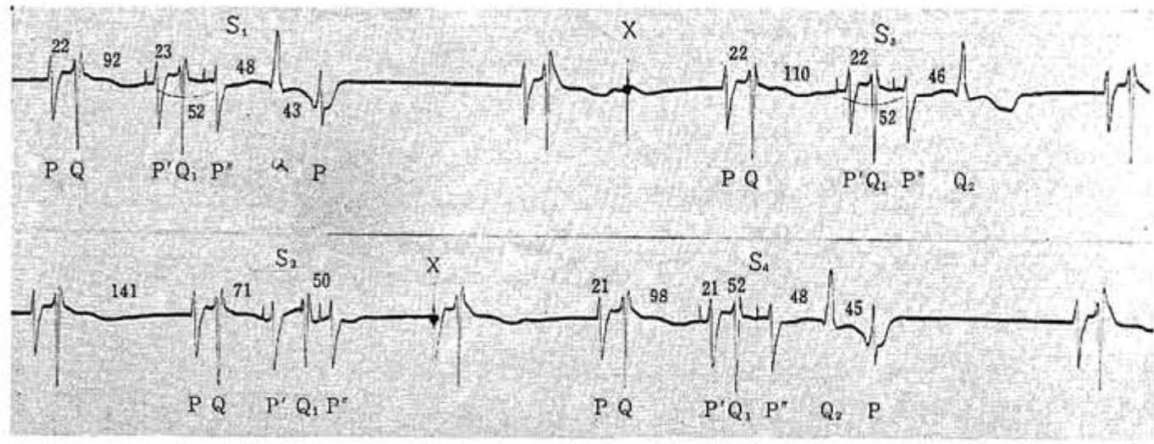

Fig. 8. The double stimuli experiment. Each of four stimuli produces two successive AES.s. The interval between $\mathrm{P}^{\prime}$ and $\mathrm{P}^{\prime \prime}$ is fairly constant. According to the coupling time of $\mathrm{P}^{\prime}$, the second antegrade impulse produces again the retrograde $\mathrm{P}$-wave $\left(\mathrm{S}_{1}, \mathrm{~S}_{4}\right)$, or is blocked $\left(\mathrm{S}_{3}\right)$ or is followed by a ventricular complex only $\left(\mathrm{S}_{2}\right)$.

I. VES. arises the more prolonged the conduction of the next sinus impulse is. Such relation existed in all cases.

2. Artrial extrasystoles:

Similar experiments were performed with the stimulation of the atrium, the A-V conduction system being depressed with procain-amide, but it was far more difficult to produce atrial extrasystoles (AES.) which again returned to the atrium. We could not obtain the record of reversed reciprocal rhythm by the single stimulation of the atrium, and only 3 cases of this rhythm were hitherto obtained in the double stimuli experiments. One of the causes of difficulty was the appearance of spontaneous AES.s which followed the 2 successive AES.s induced by the stimulation.

Fig. 8 illustrates the record of 2 successive atrial stimulation. The antegrade impulse of the second AES. sometimes returns again to the atrium $\left(\mathrm{S}_{1}\right.$ or $\left.\mathrm{S}_{4}\right)$. This is the rare case of reversed reciprocal rhythm experimentally 


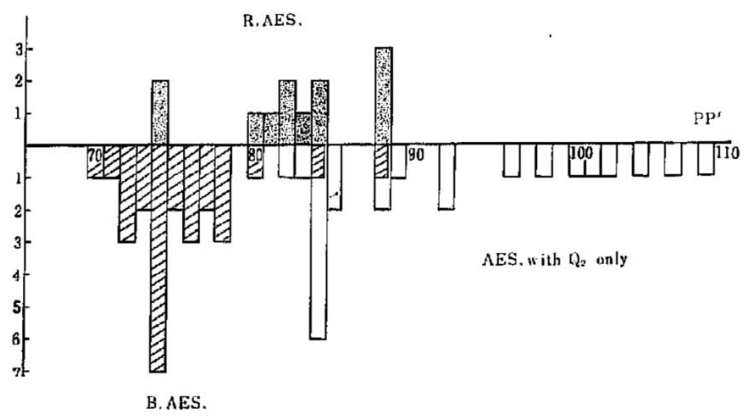

Fig. 9. Distribution of $\mathrm{PP}^{\prime}$ in the double stimuli experiment. "Same scale as in Fig. 3 or Fig. 4.

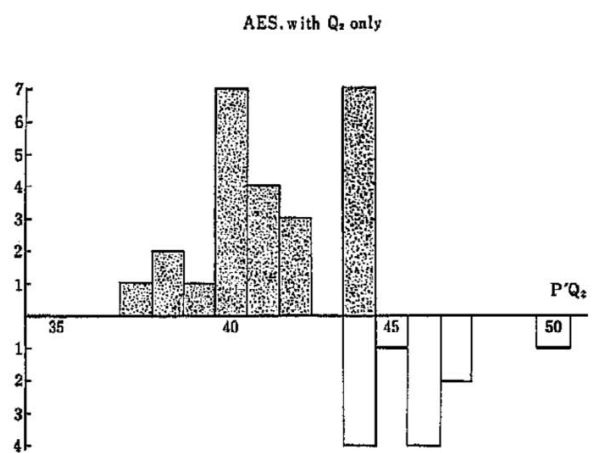

R.AES.
Fig. 10. Antegrade conduction time of the second AES. in the double stimuli experiment. AES. with longer conduction time returns again to the atrium.

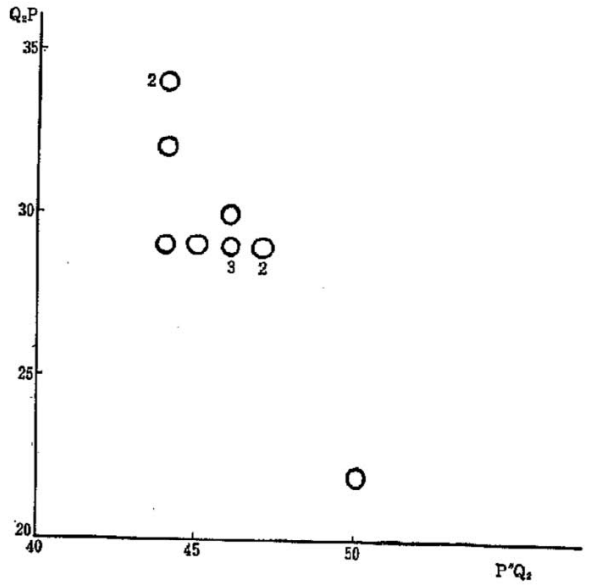

Fig. 11. Correlation between the antegrade conduction time of the R. AES. and the retrograde conduction time of the returning impulse.

produced under the sinus rhythm. According to the coupling time of the first AES., the second atrial impulse was blocked or conducted to the ventricle with or without returning to the atrium. The distribution of the coupling $\left(\mathrm{PP}^{\prime}\right)$ is illustrated in Fig. 9. 
Antegrade conduction time $\left(\mathrm{P}^{\prime \prime} \mathrm{Q}_{2}\right)$ of the second AES. was examined about the AES.s which were conducted to the ventricle. As illustrated in Fig. 10 those AES.s having the longer antegrade conduction time return to the atrium.

Retrograde conduction time of the reciprocating impulse was measured as $Q_{2} P$ (the time interval from the beginning of $Q_{2}$ to the beginning of $P$ ), and there was negative correlation between $\mathrm{P}^{\prime \prime} \mathrm{Q}_{2}$ and $\mathrm{Q}_{2} \mathrm{P}$ as illustrated in Fig. 11.

\section{Discussion}

It is widely accepted clinically and experimentally that the impulse of the VES. can be conducted in retrograde fashion to the atrium if the A-V condution system is not in the refractory state. If this system is depressed by some drugs, the induced VES. cannot be conducted backwardly and I. VES.s of various couplig can be recorded. The retrograde impulse of I. VES. leaves some influence upon the lower end of the A-V conduction system, thus lengthening in various extent the conduction time of next sinus impulse.

If the I. VES. arises early in diastole, the next sinus impulse reaches after longer time interval the point where the retrograde impulse stops. Accordingly there exists negative correlation between $Q^{\prime} P$ and $P_{1} Q_{1}$ as illustrated in Fig. 7.

If the conductivity of the A-V conduction system becomes a little better and if the longitudinal functional dissociation exists, the retrograde impulse may be conducted to the atrium through the pathway which has shorter refractory period and may return to the ventricle forming a reciprocal beat. Thus the I.VES. theoretically bears a close relationship with the R. VES. In our experiment VES.s with shorter coupling tended to form I. VES. and those with longer coupling tended to form the R. VES.

Concerning the retrograde conduction of the R. VES., it is natural to suppose there should be negative correlation between $Q^{\prime} P_{1}$ or $Q^{\prime \prime} P_{2}$ and the coupling of $Q^{\prime}$ or $Q^{\prime \prime}$ respectively. This was true in our experimental data.

We cannot decide the point where the retrograde impulse engages another pathway and changes its direction. If the point is near the upper end of the A-V conduction system, we may select $P_{1} Q_{1}$ or $P_{2} Q_{2}$ as the antegrade conduction time of the reciprocal beat. This value appeared to have negative correlation with the retrograde conduction time of the VES. In most cases it bore no correlation with $\mathrm{PP}_{1}$ which means the time interval while the retrograde impulse of the R. VES. reached the upper end after the preceding sinus impulse passed this point. In the case of $\mathrm{R}$. VES. the lower part of the returning pathway should be penetrated by the retrograde impulse. If the retrograde conduction time is too long, the returning impulse reaches later the point where the retrograde impulse stops, thus being transmitted rapidly. 
In the experiment of the atrial stimulation there seems to exist similar law of the conduction, but to produce the reversed reciprocal rhythm is very difficult. It may in part be due to the difference in the structure of the conductive tissue at the upper or lower end. We succeeded to produce this arrhythmia under the sinus rhythm in only 3 experiments, and similar relations as in the experiment of VES. were found about the distribution of the coupling time, the conduction time of the second AES., and the correlation between the retrograde conduction time of the returning impulse and the antegrade conduction time of the second AES.

\section{Strmmary}

By depressing the a-v conduction system mainly with procain amide injection, 3 kinds of VES.s or AES.s were produced in the experiments on dogs.

(1) According to the coupling time of the VES., the retorgrade impulse was completely blocked or partially conducted with a reciprocal beat or conducted through whole pathway to the atrium. Similar relationship was observed in the experiments of AES.s, although it was far more difficult to produce a reversed reciprocal rhythm.

(2) The retrograde conduction time of $\mathrm{R}$. VES. was longer than that of the VES. with a retrograde P-wave only, and had negative correlation with the coupling time of R. VES. and the antegrade conduction time of the reciprocal beat.

(3) The antegrade conduction time of the R. AES. was longer than that of the AES. conducted to the ventricle only, and had negative correlation with the retrograde conduction time of the reciprocating impulse.

(4) The conduction time of the first sinus impulse after the I. VES. had negative correlation with the interval between the VES. and the next sinus impulse.

(Published in Respiration and Circulation 6:565,1958 in Japanese)

\section{REFERENGES}

1. White, P. D.: Arch. Int. Med. 16: 517, 1915.

2. Decherd, G. and Ruskin, A.: Texas Rep. Biol. \& Med. 1: 299, 1943.

3. Bix, H.: Am. Heart J. 41: 448, 1951.

4. Cutts, F. B.: Am. Heart J. 14: 717, 1951.

5. Schott, A.: Proc. Roy. Soc. Med. 44: 151, 1951.

6. Drury, A. N.: Heart 11 : 405, 1924.

7. Bain, C.W.C.: Lancet. 1: 26, 1938.

8. Samojloff, A. und Tschernoff, A.: Ztschr. ges. Exp. Med. 71: 768, 1930.

9. Perelman, J. S. and Miller, R.: Am. Heart J. 33: 34, 1947.

10. Grau, S. and Gouaux, J. L. : Circulation 2: 422, 1950.

11. Kistin, A. D. and Landown, M. : Circulation 3, 738, 1951.

12. Levine, E.: Rev. Argent. Cardiol. 8 : 197, 1941. 
13. Scherf, D. and Shookhoff, C.: Wien. Arch. inn. Med. 12, 501, 1926.

14. Mines, G. R.: J. Physiol. 46 : 349, 1913.

15. Mendez, G., Gruhzit, G. G., and Moe, G. K.: Am. J. Physiol. 184: 287, 1956.

16. Moe, G. K., Preston, J. B., and Burlington, H.: Circulation Research 4: 357, 1956.

17. Rosenblueth, A.: Am. J. Physiol. 194: 495, 1958.

18. Katz, L. N., and Pick, A.: Glinical Electrocardiography, Part I, The Arrhythmias, Lea \& Febiger, Philadelphia, p. 623 (Fig. 364), 1956.

19. Zakopoulos, K. S.: Am. Heart J. 534: 291, 1957.

20. Soloff, L. A. and Zatuchni, J.: Am. Heart J. 54, 635, 1957.

21. Wolferth, C. C.: Am. Heart J. 4: 521, 1929.

22. Naim, M.: Am. Heart J. 29 : 398, 1945.

23. Eldridge, F. L. : Am. Heart J. 55 : 469, 1958.

24. Mita, Y., Dohi, Y., Matsuura, Y. and Dohi, I.: Igakuto Seibutsugaku 32: 4, 1954 (In Japanese).

25. Dohi, I., Tada, T., Mita, Y., Dohi, Y., Matsuura, Y., and Maruyama, R. : Jap. Circulation J. 20: 448, 1956 (In Japanese). 